\title{
Mechanisms underlying the increased chemosensitivity of bortezomib-resistant multiple myeloma by silencing nuclear transcription factor Snail1
}

\author{
ZHENQI HUANG, XINGLIN LIANG, WEI WU, XIAOWEN CHEN, QINGSHU ZENG, \\ MINGZHEN YANG, JIAN GE and RUIXIANG XIA \\ Department of Hematology, The First Affiliated Hospital of Anhui Medical University, \\ Anhui Medical University, Hefei, Anhui 230032, P.R. China
}

Received May 2, 2018; Accepted October 9, 2018

DOI: 10.3892/or.2018.6797

\begin{abstract}
The Snail family transcriptional repressor 1 gene (Snail1) was screened in multiple myeloma cells (MMCs) from bortezomib-resistant MM patients and was found to be significantly associated with the development of drugresistance mechanisms. In the present study, we first confirmed that the protein expression of Snail1 in bortezomib-resistant MMCs was significantly higher than that in MMCs without bortezomib resistance. The mechanistic studies confirmed that the enhancement of Snaill expression in bortezomib-resistant MMCs directly upregulated transcription of the intracellular MDR1 gene to immediately develop multiple drug resistance mechanisms and inhibited P53 protein expression through the Snail1/hsa-miRNA-22-3p/P53 pathway to inhibit tumor cell apoptosis. By upregulating MDR1 and downregulating P53, Snaill induced the drug resistance of MMCs to bortezomib, while Snaill gene silencing effectively improved the drug sensitivity of MMCs to bortezomib chemotherapy. The present study further elucidated the drug resistance mechanisms of MMCs and provides evidence for increased clinical efficacy of bortezomib in MM patients.
\end{abstract}

\section{Introduction}

Multiple myeloma (MM) is a malignant hematological tumor with monoclonal plasma cell hyperplasia. The incidence of MM in European and American countries has already surpassed acute leukemia and accounts for $12 \%$ of all

Correspondence to: Professor Jian Ge or Professor Ruixiang Xia, Department of Hematology, The First Affiliated Hospital of Anhui Medical University, Anhui Medical University, 218 Jixi Road, Hefei, Anhui 230032, P.R. China

E-mail: gejian52@163.com

E-mail: xrx2041@163.com

Key words: Snail1, hsa-miRNA22-3p, MDR1, P53, bortezomib, multiple myeloma cells, resistance hematologic malignancies (1). Currently, the major clinical treatment strategy for MM is chemotherapy (2). However, effective chemotherapeutic drugs are still limited by the development of drug resistance mechanisms. Therefore, the effects of chemotherapy are greatly reduced (3). Bortezomib has achieved great progress in MM treatment. As a proteasome inhibitor, bortezomib inhibits the tumor activity of multiple myeloma cells (MMCs) through various routes (4-7). As the first-line drug in MM chemotherapy, bortezomib has significant inhibitory functions in the biological progression and pathological progression of myeloma. However, secondary drug resistance accompanied by chemotherapy usually results in the poor chemotherapeutic effects of bortezomib and poor prognosis in MM (8-11). Thus, studies related to MM drug resistance mechanism are a research 'hotspot' in the field of MM chemotherapy.

Firstly, we found that the expression of Snail family transcriptional repressor 1 (Snail1) was significantly increased in MMCs from bortezomib-resistant MM patients. In this study, an in vitro resistance model was constructed to investigate the reasons for the abnormal expression of Snaill during the development of bortezomib resistance and its contribution to resistance. Data analyses showed that Snaill had a positive association and a negative association with the expression of the MDR1 gene and P53 protein, respectively $(12,13)$. Subsequent studies concerning the mechanisms were based on the following three confirmed facts. The Snaill nuclear transcription factor directly binds to the multi-drug resistance gene (MDR1) promoter to positively regulate gene transcription. Snaill binds to the hsa-miRNA-22-3p precursor promoter to positively regulate its transcription. Finally, hsa-miRNA-22-3p binds to the 3'UTR region of the tumor protein p53 gene (P53) to negatively regulate its protein expression. Pathway-specific analysis using Snail1 gene silencing confirmed that the Snail1/ MDR1 and Snail1/hsa-miRNA-22-3p/P53 pathways dominated the reversal of drug resistance in bortezomib-resistant MMCs. For the first time, this study confirmed the critical role of the Snail1 nuclear transcription factor in the regulation of the drug resistance mechanisms in bortezomib-resistant MMCs and preliminarily elucidated the pathways of the decreased drug resistance of MMCs to bortezomib by Snaill silencing. 
Research data showed that Snaill affects the development of bortezomib drug resistance mechanisms in MMCs through regulation of the expression of MDR1 and P53.

In addition, to the best of our knowledge, this was the first study on the association between hsa-miRNA-22-3p and the drug resistance mechanisms in MMCs. Based on the mechanistic study, we aimed to improve the effect of bortezomib on MM by silencing Snaill. In the long run, the study provides support for elucidating the development of resistance of MM, and new insight on possible solutions. For the clinical treatment of MM, this study may guide the development of novel combination therapy including gene intervention combined chemotherapeutics to minimize the resistance of MM to bortezomib.

\section{Materials and methods}

Cell culture. The human multiple myeloma cell lines, XG-7 and RPMI-8226, were purchased from the Cell Bank of the Chinese Academy of Sciences (CBCS; Shanghai, China). The establishment of bortezomib-resistant cell lines, XG-7/Bor and RPMI-8226/Bor, was performed using the gradient induction method by our study group. Drug-resistant cells were cultured in Invitrogen ${ }^{\mathrm{TM}}$ RPMI-1640 culture medium (Thermo Fisher Scientific, Inc., Waltham, MA, USA) containing $10 \%$ fetal bovine serum (FBS; Invitrogen; Thermo Fisher Scientific, Inc.) and $10 \mathrm{nM}$ bortezomib (Sigma-Aldrich; Merck KGaA, Darmstadt, Germany) under culture conditions of $37^{\circ} \mathrm{C}$ and $5 \%$ $\mathrm{CO}_{2}$. Cells showed semi-suspension growth, and cell passage was performed using the centrifugation method. In addition, 293T cells were purchased from the American Type Culture Collection (ATCC, Manassas, VA, USA) and were used as the tool and virus package cell line, and they were cultured in high-glucose DMEM culture medium (Invitrogen; Thermo Fisher Scientific, Inc.) containing $10 \%$ FBS under culture conditions of $37^{\circ} \mathrm{C}$ and $5 \% \mathrm{CO}_{2}$. These cells showed adherent growth and were passaged using trypsin digestion (Invitrogen; Thermo Fisher Scientific, Inc.) method when cell confluence reached $70 \%$.

Collection of MMCs from MM patients with bortezomibresistance and detection of related indictors. Primary MMCs were collected before and after development of bortezomib resistance from $20 \mathrm{MM}$ patients treated at the First Affiliated Hospital of Anhui Medical University, China (from January 2016 to December 2017). Eligible patients exhibited refractory/relapse to their therapy after at least two cycles of bortezomib (administered in combination with other agents), defined as no response (less than partial response) or progression either during therapy or $\leq 60$ days after completion of therapy. The baseline characteristics of the patients at diagnosis are shown in Table I. Informed consent was provided by all patients in writing and the study was approved by the Medical Ethics Committee of the First Affiliated Hospital of Anhui Medical University. MMCs were obtained by fluorescence-activated cell sorting for $\mathrm{CD} 38^{+} \mathrm{CD} 45^{+}$mononuclear cells, about $1 \times 10^{7}$ cells from each sample, collected by centrifugation after phosphate-buffered saline (PBS) resuspension, placed in cell cryopreservation tubes, labeled and stored in liquid nitrogen. Total RNA and protein were extracted, and the relative levels of Snail1, hsa-miRNA-22-3p, MDR1, and P53 were detected using real-time PCR, and the protein expression levels of Snail1, P-gp (protein encoded by the MDR1 gene) and P53 were detected using western blot analysis.

Construction of vectors and RNA synthesis. Construction of cDNA expression vector. The coding sequence (CDS) of human MDR1 (NM_001348945.1) was amplified by using the primers 5'-GGAATTCGCCACCATGAGTGTCAAC TTGCAA-3' and 5'-CGGGATCCTCACTGGCGCTTTG TTCCAG-3', which contain an EcoRI cutting site and kozak sequence and a BamHI cutting site, respectively, with the cDNA prepared by reverse transcription of RNA isolated from XG-7/Bor cells. The PCR product was digested and cloned into the pcDH1 lentiviral expressing vector (System Biosciences, Palo Alto, CA, USA); the recombinant vector was named pcDH1-MDR1.

Construction of the shRNA vector. A siRNA sequence complementarily binding to human Snail1 (NM_005985.3) was chosen. The target sequences of siRNA (5'-GCTCTGTGG CATTCACGCA-3') were homologous to Snaill, respectively. The oligonucleotide templates of these shRNAs were chemically synthesized and cloned into the linear pshRNA-copGFP shRNA vector (System Biosciences) which was obtained through digestion by BamHI and EcoRI (Takara Biotechnology Co., Ltd., Dalian, China) and purification by agarose gel electrophoresis. An invalid siRNA sequence (5'-TTGCAGCCA GTGGCTTACC-3') was used as a negative control (NC). Sequencing was used to confirm the vectors constructed (pshRNA-Snail1 and pshRNA-NC), and pshRNA-P53 for the human P53 gene (NM_000546.5) was constructed by the same method (siRNA, 5'-GACTCCAGTGGTAATCTAC-3').

Construction of the luciferase reporter vector. The 3'-untranslated region (3'UTR, 212 bp) of human P53 was amplified from cDNA obtained through the reverse transcription of total RNA of XG-7/Bor cells, with the following primers: 5'-GCTCTAGAGGCATTTGCACCTACCTC-3' and 5'-GCT CTAGATTGGCTGGGCCAGCAGAGAC-3'. The amplification parameters were as follows: 32 cycles of denaturation at $95^{\circ} \mathrm{C}$ for $10 \mathrm{sec}$, annealing at $58^{\circ} \mathrm{C}$ for $30 \mathrm{sec}$ and extension at $72^{\circ} \mathrm{C}$ for $30 \mathrm{sec}$. The product was digested with $\mathrm{XbaI}$ and inserted into the pGL3-promotor vector (Promega, Madison, WI, USA). TargetScan (http://www.targetscan.org/vert_71/) was used to predict the theoretic target (seed region) of hsa-miRNA-22-3p in the 3'UTR of the P53 mRNA sequence. The seed region was mutated from 5'-GGCAGCT-3' to 5'-TCGAGCG-3 by point mutation. The resultant vectors were termed pGL3-wt- P53 and pGL3-mt-P53 respectively.

The promoters of MDR1 and hsa-miRNA-22-3p were amplified by using human genomic DNA as a template and cloned into a luciferase reporter vector pGL3-Enhancer (Promega) upstream of the luciferase gene. We constructed the wild-type transcription factor binding site (TFBS) vectors, pGL3-wt-pro-P53 and pGL3-wt-pro-miRNA-22. We then constructed the mutant-type TFBS vectors pGL3-mt-pro-P53 and pGL3-mt-pro-miRNA-22 through the point mutation, 5'-CCGCTG-3' to 5'-CAGGCT-3'. The products of the vectors were confirmed by DNA sequencing. Endotoxin-free DNA was prepared in all cases. 
Table I. Baseline characteristics of the MM patients $(\mathrm{N}=20)$ at diagnosis.

\begin{tabular}{|c|c|}
\hline Characteristics & Data \\
\hline Median age (range), in years & $58.2(35-76)$ \\
\hline \multicolumn{2}{|l|}{ Sex } \\
\hline Male, n (\%) & $11(55)$ \\
\hline Female, n (\%) & $9(45)$ \\
\hline \multicolumn{2}{|c|}{ Serum heavy chain at diagnosis, $\mathrm{n}(\%)$} \\
\hline None & $3(15)$ \\
\hline IgG & $11(55)$ \\
\hline $\operatorname{Ig} \mathrm{A}$ & $5(25)$ \\
\hline $\operatorname{IgD}$ & $1(5)$ \\
\hline \multicolumn{2}{|l|}{ ECOG score at diagnosis, $\mathrm{n}(\%)$} \\
\hline 0 & $1(5)$ \\
\hline 1 & $3(15)$ \\
\hline 2 & $6(30)$ \\
\hline 3 & $7(35)$ \\
\hline 4 & $2(10)$ \\
\hline 5 & $1(5)$ \\
\hline \multicolumn{2}{|l|}{ ISS stage at diagnosis, $\mathrm{n}(\%)$} \\
\hline Stage I & $4(20)$ \\
\hline Stage II & $6(30)$ \\
\hline Stage III & $10(50)$ \\
\hline \multicolumn{2}{|l|}{ FISH at diagnosis } \\
\hline del17p & $4(20)$ \\
\hline $1 \mathrm{q} 21$ & $3(15)$ \\
\hline $\mathrm{t}(4 ; 14)$ & $1(10)$ \\
\hline
\end{tabular}

MM, multiple myeloma; F, female; M, male; ECOG, Eastern Cooperative Oncology Group; ISS, International Staging System; FISH, fluorescent in situ hybridization.

RNA synthesis. Chemically synthesized hsa-miRNA-22-3p mimics (5'-AAGCUGCC AGUUGAAGAACUGUtt-3'), inhibitor (5'-ACAGUUCUUCAACUGGCAGCUUtt-3') and NC (5'-CGAAUACAGAAAGGCGUUCUGUtt-3') were obtained from Sangon (Shanghai, China), ' $\mathrm{tt}$ ' protective bases being added to the RNA end.

Packaging of the recombinant lentivirus and infection of $X G-7 / B$ or and RPMI-8226/Bor cells with the lentivirus. One day before transfection, $293 \mathrm{~T}$ cells were seeded into $10-\mathrm{cm}$ dishes. Two micrograms of each vector (pshRNA-Snaill or pcDH1-MDR1 or pshRNA-P53) and $10 \mu \mathrm{g}$ pPACK Packaging Plasmid Mix (System Biosciences) were co-transfected using Lipofectamine 2000 (Invitrogen; Thermo Fisher Scientific, Inc.) in accordance with the manufacturer's protocol. The medium was replaced with DMEM plus $1 \%$ FBS. Forty-eight hours later, the supernatant was harvested and then cleared by centrifugation at $5000 \mathrm{x} \mathrm{g}$ at $4^{\circ} \mathrm{C}$ for $5 \mathrm{~min}$ and passed through a $0.45-\mu \mathrm{m}$ polyvinylidene fluoride (PVDF) membrane (Millipore). The titer of the virus was determined by gradient dilution. The packaged lentiviruses were named as Lv-shRNASnail1 or Lv-MDR1 or Lv-shRNA-P53.
One day before viral infection, XG-7/Bor and RPMI-8226/ Bor cells in the logarithmic phase were made into a suspension, and the number of viable cells was counted by using trypan blue staining. Cells were collected by centrifugation at $1000 \times \mathrm{g}$ and re-suspended in RPMI-1640 medium (10\% FBS and $10 \mathrm{nM}$ bortezomib) at a concentration of $5 \times 10^{5}$ cells $/ \mathrm{ml}$. Cells were seeded on 6-well plates, $2 \mathrm{ml} /$ well, and cultured overnight under normal conditions. One day after seeding, the cells were infected with lentiviruses diluted with dPBS at an MOI (multiplicity of infection) of 20 , and the medium was refreshed after $24 \mathrm{~h}$. The infection efficiency was assessed by fluorescence microscopy $72 \mathrm{~h}$ after infection. Total protein was extracted from the cells using the M-PER Mammalian Protein Extraction Reagent kit (Thermo Fisher Scientific, Inc.) and subjected to western blotting to measure the levels of Snaill, P-gp and P53.

\section{Luciferase assay}

Verification of the binding site of hsa-miRNA-22-3p on P53 3'UTR. 293T cells were transfected with the hsa-miRNA22-3p-mimics or inhibitor or NC, and pGL-wt-P53 or pGL-mt-P53 using Lipofectamine 3000 (Invitrogen; Thermo Fisher Scientific, Inc.) according to the manufacturer's instructions. Forty-eight hours after transient transfection, the cells were harvested, and luciferase assays were performed.

Verification of the binding site of the transcription factor in MDR1 and the pri-miRNA-22 promoter. 293 T cells were co-transfected with the wild-type or mutant promoter reporter vectors and pshRNA-snail1, and harvested for luciferase activity assay $48 \mathrm{~h}$ later. The transfection experiment was carried out in 24-well plates, following the instructions for Lipofectamine 3000. PGL-TK (100 ng) was transfected for each well as the internal reference for the luciferase assay. The relative luciferase activities (ratios of firefly and Renilla luciferase activity) of the lysates were measured by dual luciferase reporter assay system (Promega).

Assessment of cell viability and $I C_{50}$ values. The two genetically engineered cell lines were seeded in 96-well plates at $5 \times 104$ cells/well, and bortezomib was added to a final concentration of $1,2,4,8,16$ or $32 \mathrm{nM}$ for a period of $48 \mathrm{~h}$, followed by a CCK-8 (Cell Counting Kit-8) assay for cell viability. Briefly, $10 \mu$ l CCK-8 solution was added, and the cells were cultured under normal conditions for an additional $4 \mathrm{~h}$ before measuring absorbance at $450 \mathrm{~nm}$. The cell inhibition ratio was calculated, based on the $\mathrm{IC}_{50}$ values at $48 \mathrm{~h}$.

Detection of apoptosis. Seventy-two hours after viral infection, XG-7/Bor cells were seeded in 6-well plates at $1 \times 10^{5}$ cells per well in medium containing $10 \mathrm{nM}$ bortezomib and were cultured for $48 \mathrm{~h}$. The cells were collected and measured for apoptosis using flow cytometry (FACS Calibur; BD Biosciences, Franklin Lakes, NJ, USA) after treatment using Annexin V:FITC Apoptosis Detection Kit II (cat. no. 556570; BD Biosciences). Cells were made into suspensions by trypsinization and the cells were washed with dPBS and suspended in $500 \mu \mathrm{l}$ binding buffer and $5 \mu \mathrm{l}$ Annexin V-FITC was added and the cells were maintained in the dark for $10 \mathrm{~min}$. Cells were then stained with $5 \mu \mathrm{l}$ propidium iodide (PI) for $5 \mathrm{~min}$. 
A

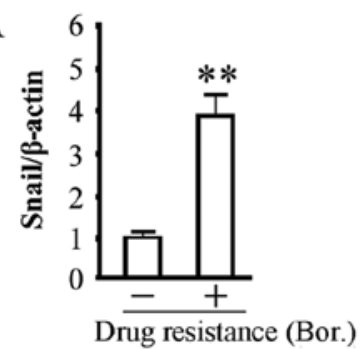

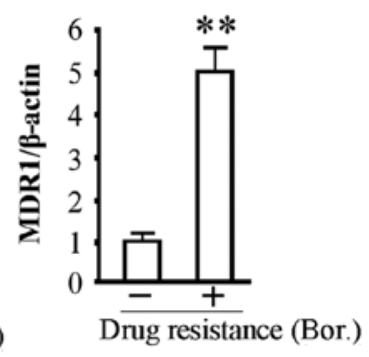

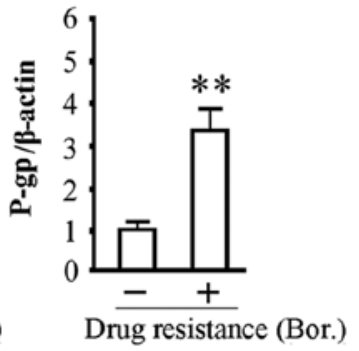

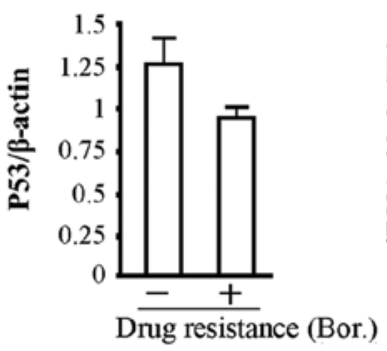
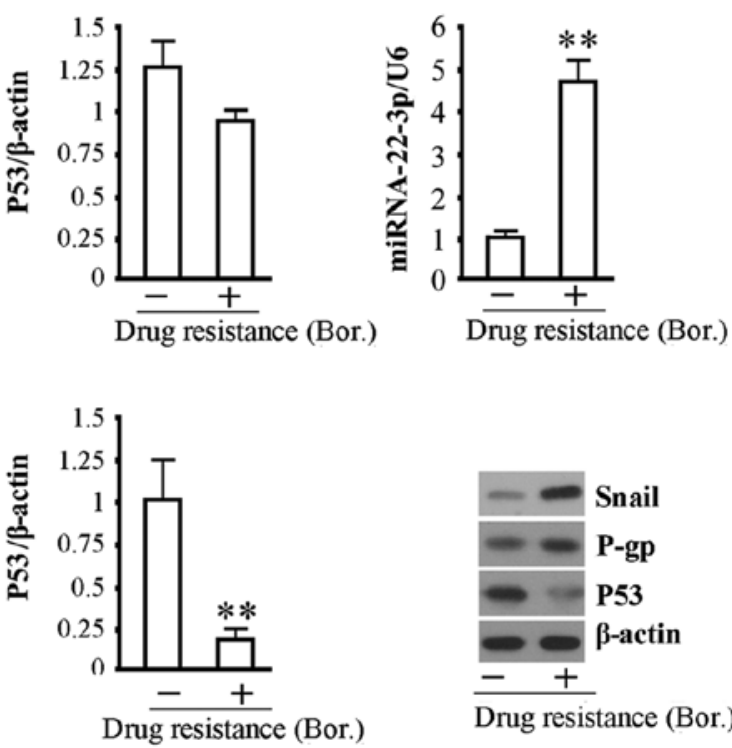

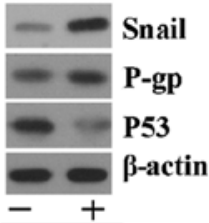

Drug resistance (Bor.)

Figure 1. Fluorescence quantitative and western blot analyses of MMCs from MM patients before and after the development of drug resistance to bortezomib. (A) Analyses of relative levels of Snail1, MDR1 and P53 mRNAs and hsa-miRNA-22-3p. The relative values of target genes between groups were analyzed using the $2^{\Delta \Delta C q}$ method. $\beta$-actin and U6 were used as the internal controls for quantitative detection of mRNAs and hsa-miRNA-22-3p, respectively. (B) Detection of the protein expression of Snail1, P-gp, and P53 in MMCs. $\beta$-actin was used as the internal control protein. The left panels show the analysis of optical density values among target protein bands, and the right image shows the exposed X-ray film of the target bands. The target band sizes of Snaill, P-gp and P53 proteins were 69,32 and $53 \mathrm{kDa}$, respectively. The molecular weight of $\beta$-actin was $37 \mathrm{kDa}$. All data are expressed as the mean \pm SD. The sample size of the group was $\mathrm{n}=20$. ${ }^{* *} \mathrm{P}<0.01$. MMCs, multiple myeloma cells; MM multiple myeloma.

Apoptosis was analyzed on BD-FACSCalibur using FITC (FL1) channel and PI (FL2) channel at an excitation wavelength at $488 \mathrm{~nm}$.

Real-time PCR. Total RNA was isolated with TRIzol reagent (Invitrogen; Thermo Fisher Scientific, Inc.) according to the manufacturer's instructions and was reversely transcribed into cDNA using M-MLV Reverse Transcriptase and oligo(dT)18 primer (Takara). The following specific primers were used for the quantitative PCR of human Snail1, MDR1, P53 and $\beta$-actin: Snail1, 5'-ATGCCGCGCTCTTTGCTC-3' and 5'-GGTG GGCCTGGTCGTAG-3'; MDR1, 5'-CCGTGGGGCAAGTC AGTTCA-3' and 5'-CCGGTCGGGTGGGATAGTTG-3'; P53, 5'-CGTACTCCCCTGCCCTCAACAAGA-3' and 5'-GCA GCGCCTCACAACCTCCGTCAT-3'; and $\beta$-actin, 5 '-CCT GTACGCCAACACAGTGC-3' and 5'-ATACTCCTGC TTGCTGATCC-3'. The lengths of the amplified products were 118, 186, 155 and $211 \mathrm{bp}$, respectively. Real-time PCR was performed using SYBR Premix Ex Taq ${ }^{\mathrm{TM}}$ kit and TP800 System (Takara Biotechnology). cDNA from $200 \mathrm{ng}$ total RNA was used as the template. The PCR reactions were carried out under the following conditions: 40 cycles of denaturation at $95^{\circ} \mathrm{C}$ for $10 \mathrm{sec}$, annealing at $60^{\circ} \mathrm{C}$ for $20 \mathrm{sec}$ and extension at $72^{\circ} \mathrm{C}$ for $20 \mathrm{sec}$. The mRNA levels of twistl were normalized using the $\Delta \Delta \mathrm{Ct}$ method, to the expression of an endogenous housekeeping gene, $\beta$-actin. The specific primers for hsa-miRNA-22-3p detection, U6 snRNA (NM_001101. 3), 5 ' - T A C C T T GCGA A G T GC T TA A AC-3' and hsa-miRNA22-3p, 5'-GTCGTATCCAGTGCGTGTCGTG GAGTCGGCAATTGCACTGGATACGAACAGT-3' were used for cDNA preparation. The following primers were used for quantification of human U6 snRNA and hsa-miRNA22-3p: U6 snRNA, 5'-GTGCTCGCTTCGGCAGCACAT-3' and
5'-TACCTTGCGAAGTGCTTAAAC-3', which produced a segment of $112 \mathrm{bp}$; and hsa-miRNA-22-3p, 5'-GCCGGCG CCCGAGCTCTGGCTC-3' and 5'-AAGCTGCCAGTTG AAGAACTGT-3', which produced a segment of $72 \mathrm{bp}$.

Detection of protein contents. The total protein was extracted from the cells using M-PER mammalian protein extraction reagent (Pierce; Thermo Fisher Scientific, Inc.). Equal amounts of protein (20 $\mu \mathrm{g}$ per lane) estimated by a bicinchoninic acid (BCA) protein assay kit (Pierce) were loaded onto (11\%) SDS-PAGE gels and transferred onto nitrocellulose membranes. The blots were probed with a monoclonal antibody against human Snail1 (dilution 1:400; cat. no. sc-393172), P-gp (cat. no. 1:600; cat. no. sc-13131), P53 (dilution 1:500; cat. no. sc-393031) and $\beta$-actin (dilution 1:1,000; cat. no. sc-130065) (Santa Cruz Biotechnology, Inc., Dallas, TX, USA), followed by the secondary HRP-conjugated anti-mouse antibody (cat. no. sc-516102; Santa Cruz Biotechnology). After washing, the bands were detected by chemiluminescence and imaged with X-ray film. The relative optical densities were analyzed using Image Processing software Totallab (Nonlinear Dynamics Ltd. Newcastle, UK) and $\beta$-actin was used as an endogenous reference for normalization.

Statistical analysis. The data are shown as the mean \pm SD of three independent experiments. All statistical data were analyzed using the SPSS GradPack, version 20.0, statistical software (IBM Corp, Armonk, NY, USA) and GraphPad Prism 7.0 (GraphPad Software, Inc, La Jolla, CA, USA). Comparisons between groups were analyzed using two-tailed Student's t-test or one-way ANOVA with post hoc Tukey's test. All differences were considered to be statistically significant at $\mathrm{P}<0.05$. 
A
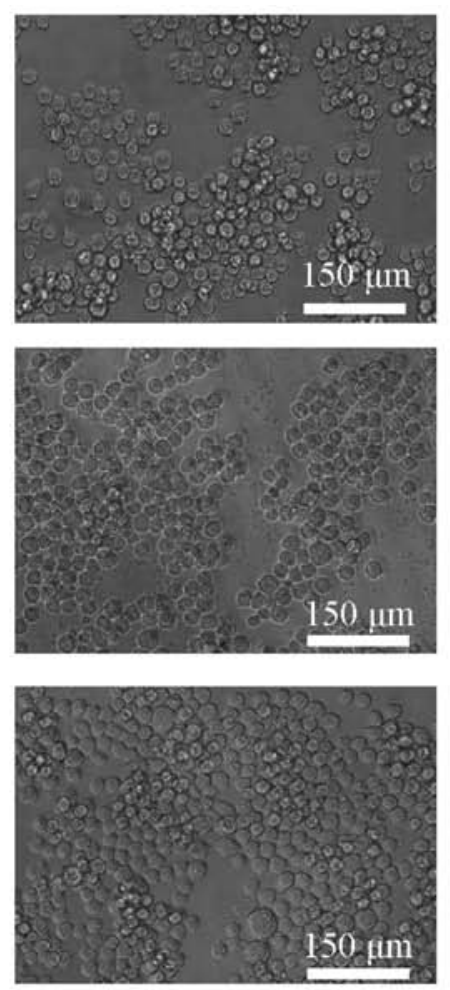
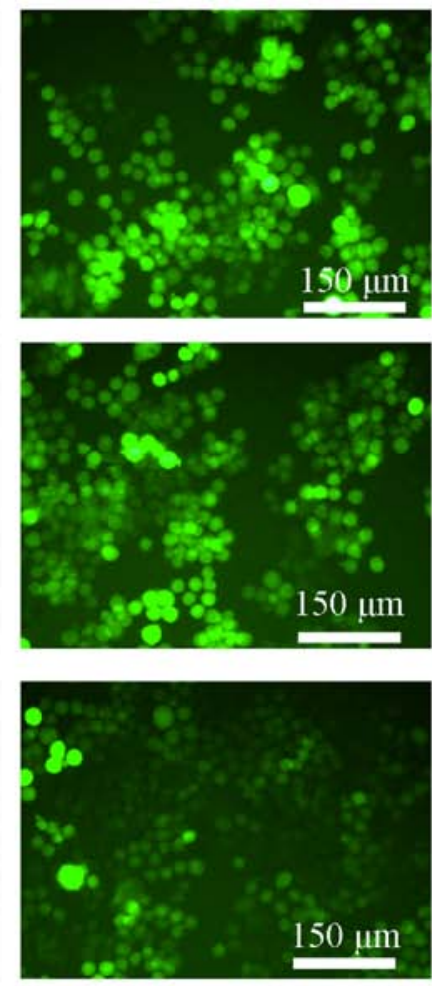

B

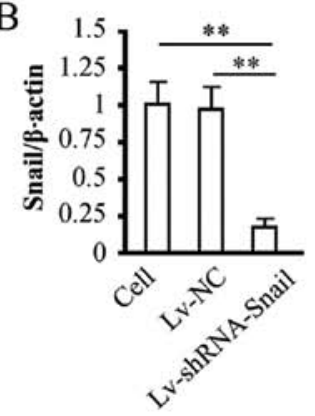

C

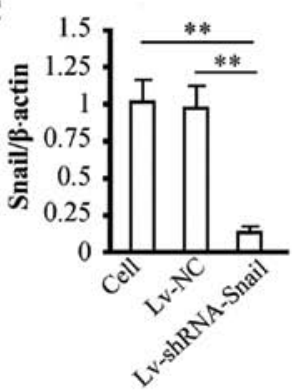

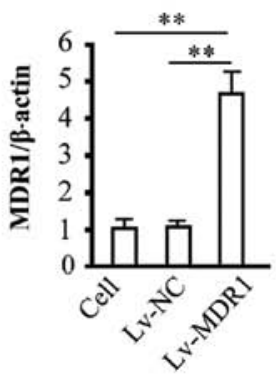
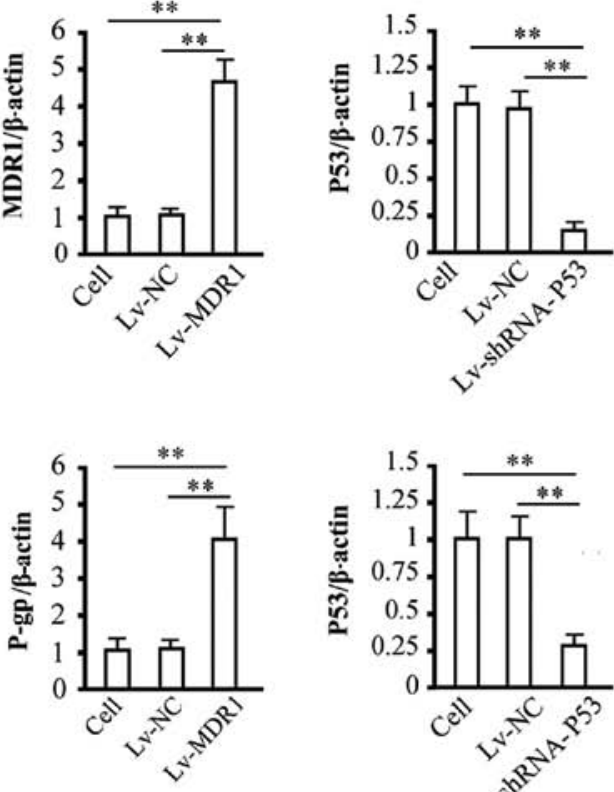

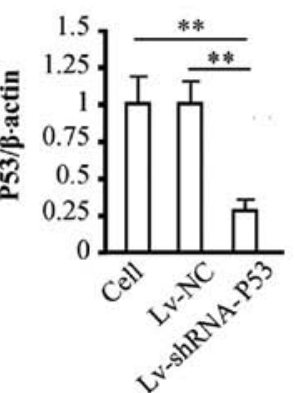

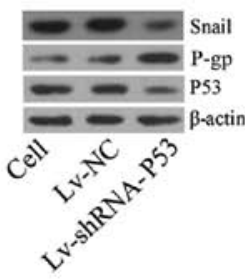

Figure 2. Detection of virus infection efficiency and gene intervention efficiency in cells. (A) Detection of infection efficiency after $72 \mathrm{~h}$ of infection with 3 groups of viruses, namely Lv-shRNA-Snail1 (upper), Lv-MDR1 (middle) and Lv-shRNA-P53 (lower) in XG-7/Bor cells. The left panels present images of cells under visible light, and the right panels present images of cells under UV excitation in the corresponding field. The virus infection efficiency in cells was estimated by dividing the number of cells with fluorescence expression by the total number of cells in the same field. In the statistical analysis, 5 fields were randomly selected to calculate the virus infection rate, and the mean value was obtained. (B) Quantitative analyses of mRNA levels of Snail1, MDR1, and P53 genes in all groups of cells after $72 \mathrm{~h}$ of recombinant virus infection. $\beta$-actin was used as the internal control. The relative level of genes was calculated using the $2^{\Delta \triangle C q}$ method. (C) Detection of the expression levels of Snaill, P-gp, and P53 proteins in all groups of cells after $72 \mathrm{~h}$ of recombinant virus infection. The left panels show the target protein bands, and the right panel shows the relative optical densities of target proteins in cells among the different groups. $\beta$-actin was used as the internal control. ${ }^{* *} \mathrm{P}<0.01$. Cell, cell control group; Lv-NC, $\mathrm{NC}$ control group.

\section{Results}

Expression of Snaill, hsa-miRNA-22-3p, MDR1 and P53 in MMCs from clinical bortezomib-resistant MM patients. The relative levels of Snail1, MDR1 and hsa-miRNA-22-3p in
MMCs were all significantly increased in MM patients after the development of bortezomib resistance, and the mRNA level of P53 was slightly lower compared with MMCs from MM patients before development of bortezomib resistance (Fig. 1A). The western blot results showed that the protein expression 
A

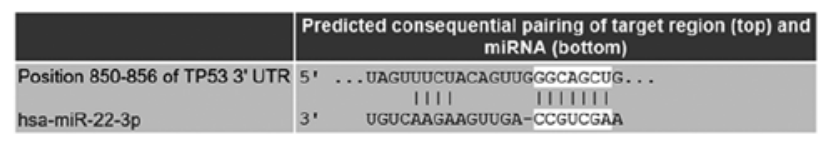

B

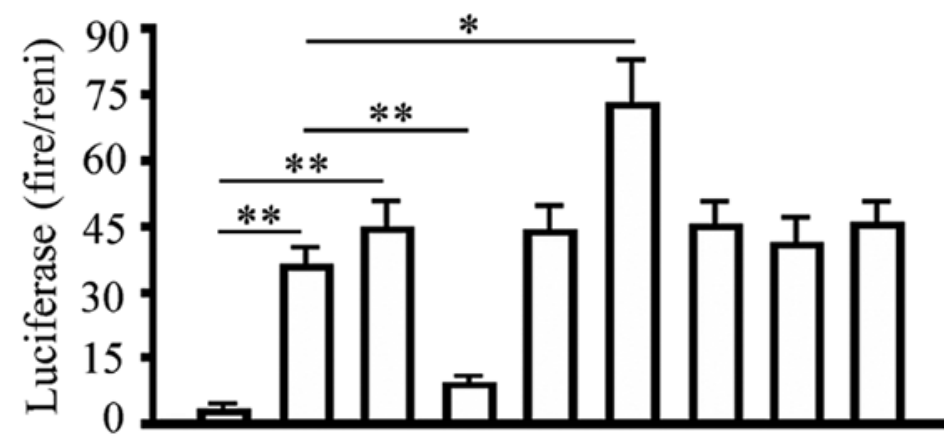

$\begin{array}{rlllllllll}\text { pGL3-wt-P53 }- & + & - & + & - & + & - & + & - \\ \text { pGL3-mt-P53 }- & - & + & - & + & - & + & - & + \\ \text { miRNA-22-3p-mimics }- & - & - & + & + & - & - & - & - \\ \text { miRNA-22-3p-inhibitor }- & - & - & - & - & + & + & - & - \\ \text { miRNA-22-3p-NC }- & - & - & - & + & - & - & + & +\end{array}$

Figure 3. Luciferase reporter activity assay for the seed region between hsa-miRNA-22-3p and the 3'UTR region of the P53 gene. (A) Prediction of the binding site of hsa-miRNA-22-3p in the 3'UTR region of the P53 gene. (B) Detection of luciferase activities. The luciferase activity was detected after $48 \mathrm{~h}$ of cotransfection in 293T cells. ${ }^{*} \mathrm{P}<0.05$ and ${ }^{* *} \mathrm{P}<0.01$.

levels of Snaill and P-gp were significantly increased and that the protein expression level of P53 was significantly decreased in MMCs with drug resistance compared with MMCs from MM patients before development of bortezomib resistance (Fig. 1B). Comprehensive analyses of these indicators showed that the abnormal expression of MMC drug resistance and apoptosis-related functional genes, namely MDR1 and P53, in MMCs with drug resistance to bortezomib resulted from inactivation of the transcription and post-transcription regulatory mechanisms, respectively. In addition, the association between hsa-miRNA-22-3p and the expression of Snaill and P53 proteins was also consistent with the transcription regulation of hsa-miRNA-22-3p by Snaill and the negative regulation of the target gene P53 by hsa-miRNA-22-3p.

Gene intervention experiment using a lentiviral approach. Using a lentiviral system, the silencing viruses targeting the Snail1 and P53 genes, namely Lv-shRNA-Snail1 and Lv-shRNA-P53, as well as the MDR1-expressing recombinant virus, Lv-MDR1, were constructed. In addition, the gene intervention effect was validated in XG-7/Bor cells. After $72 \mathrm{~h}$ of treatment with the viruses at a multiplicity of infection (MOI) of 20, the estimated virus infection efficiency was no lower than $90 \%$ in cells based on the expression of the GFP fluorescent marker (Fig. 2A). After $72 \mathrm{~h}$ of virus infection, the fluorescence quantitative detection results showed that the Snail1 and P53 gene silencing rates were 81.4 and $83.2 \%$, respectively, and that MDR1 gene expression was $\sim 4.2$-fold that of the control group (Fig. 2B). The protein expression results showed that the trends in the different groups were consistent with those of mRNA expression Fig. 2C). These results were consistent with the relationship among these proteins. In other words, Snaill silencing significantly decreased Snaill gene expression in cells, inhibited MDR1 expression and promoted P53 gene expression, while exogenous MDR1 overexpression and P53 gene silencing did not have significant effects on the expression of the Snaill gene in cells. These results directly explain the upstream and downstream regulatory relationship among these genes and proteins.

Validation of the negative regulation of MDR1 gene expression by hsa-miRNA-22-3p. TargetScan Human 7.1 analysis showed that the 3'UTR region of the P53 gene contained a 6-base seed region, namely 5'-CACUCCA-3', of hsa-miRNA22-3p (Fig. 3A). After co-transfection in 293T cells for $48 \mathrm{~h}$, relative luciferase activity showed that the hsa-miRNA-22$3 p$-mimic significantly decreased the luciferase activity of the wild-type (wt) luciferase reporter gene from $31.02 \pm 5.16$ to $5.38 \pm 0.20$. The relative luciferase activity in the hsa-miRNA$22-3 \mathrm{p}$-inhibitor transfection group increased from $31.02 \pm 5.16$ to $72.15 \pm 14.31$. For the mutant luciferase reporter gene, the difference between all co-transfection groups and the pGL3-mt-P53 alone transfection group was not significant (Fig. 3B). The above data and results indicated the presence of the predicted target site between hsa-miRNA-22-3p and the P53 gene.

Analyses of transcription regulation of $M D R 1$ and hsa-miRNA-22-3p by Snaill. Through literature review and database search, the promoter sequence of the MDR1 (ACBC1) gene was obtained (Fig. 4A). To identify the hsa-miRNA$22-3 p$ promoter, the hsa-miRNA22-3p precursor sequence, the 
A Promoter of MDR1:

5'-TTGTGCAGATTGCACGTACTTTTCCTCAGTTTGAAGTAAATAGTGGACA GGAAAAAATATTAAATGTTGGCAGTAAATATGGAAGGAAATTACAACTA ATGTAATATGCTAAAACATGCTATGTTTATTTTACTAATTTGAATTAAAAT GTAAGAATTTAAAATGCCCTGGAAAAACACGGGCATTGATCTGACGTCTC AAGTTITAAAATATTACACACTTTGAAATAGCATTTGTACCTTGAAATACC TGTCTCTATATATTTTTTAAAACTTCCTTTTTCTTTCATTCCATTTATCATCA AATAAAGGATGAACAGATGTAACTCAGAAACTGTCAAGCATGCTGAAGA AAGACCACTGCAGAAAAAATTTCTCCTAGCCTTTTCAAAGGTGTTAGGAAO CAGAAAGGTGATACAGAATTGGAGAGGTCGGAGTTTTTGTATTAACTGTA TTAAATGCGAATCCCGAGAAAATTTCCCTTAACTACGTCCTGTAGTTATAT GGATATGAAGACTTATGTGAACTTTGAAAGACGTGTCTACATAAGTTGAA ATGTCCCCAATGATTCAGCTGATGCGCGTTTCTCTACTTGCCCTTTCTAGA GAGGTGCAACGGAAGCCAGAACATTCCTCCTGGAAATTCAACCTGTTTCG CAGTTTCTCGAGGAATCAGCATTCAGTCAATCCGGGCCGGGAGCAGTCAT CTGTGGTGAGGCTGATTGGCTGGGCAGGAACAGCGCCGGGGCGTGGGCTG AGCACAGCCGCTTCGCTCTCTTTGCCACAGGAAGCCTGAGCTCATTCGAGT AGCGGCTCTTCCAAGCTCAAAGAAGCAGAGGCCGCTGTTCGTTTCCTTTA GGTCTTTCCACTAAAGTCGGAGTATCTTCTTCCAAAATTTCACGTCTTGGT3.

B
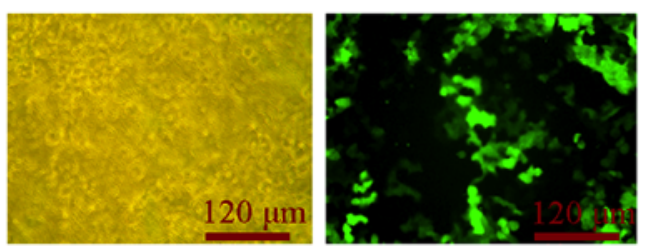

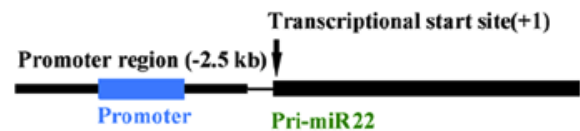

5'-AGCCCCTCACCACCTGAAGAGCCCCAGGTTGCACTGCTTTCCTTCC ACCTTACTCCACTCCACCTCTTCAGCTGGCAGACAGTCAGCAAGTCA GAGCTGTTTCCTGCAGGCTGAGAGGGAGGATTCCAGCTACTTCAAAG AATTAAGTTCATAAACCAAGAGGTGCCCCAACCAAACCTTCTCACCA AAAAGCTGAGGTCTTCCCTTCATTCTTCTACCCCCACCTCTCCAAAGG TTTAAATAATAACACTGATCTCTTAAATTATATTATATGAAATACAAA ATGTGGAAAATTTGGAAATTACAGAAAAACCAAAGATGAAAATTAC AGTGACTTTGTTCCACCATACAAAGATAACCACTCAACATTTTTTAGT ATGCCTTCCGTCTTTTTTATCTGCTCTACGTATACAAGCATACACCCA TATTTTAAAAAACAAAATTGAAATCACATAACATGCACTATTTTTAC AACCTTTTAATATTCAAGGAGCATTTTTCTTTCAGTCAGATGTT-3'
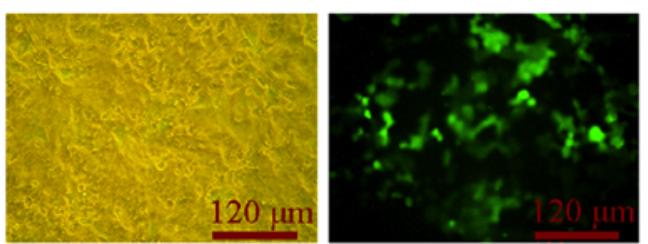

$\mathrm{C}$

Site-directed mutagenesis

TFBS (wild-type)

$\longrightarrow$ TFBS (mutant type)

5'-CAGCTG-3'

5'-CAGGCT-3'
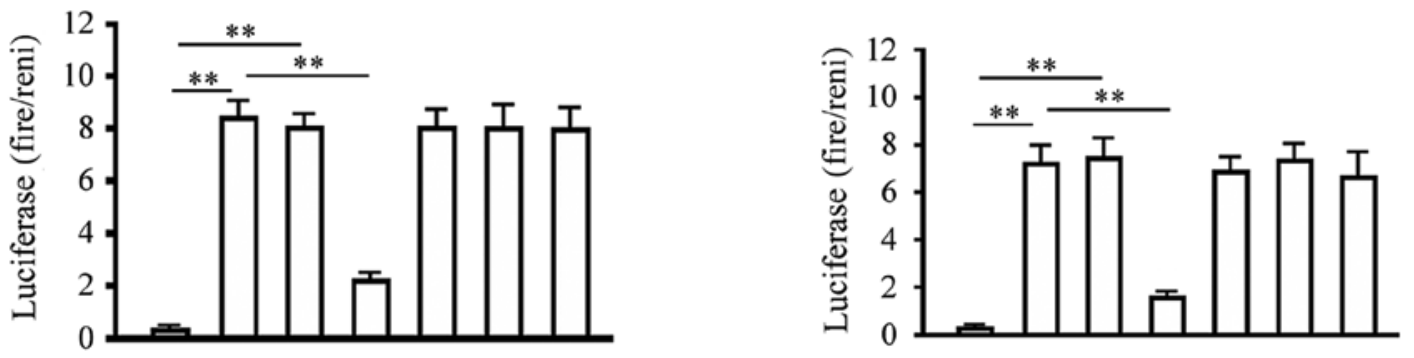

\begin{tabular}{|c|c|c|c|c|c|}
\hline pGL3-wt-pro-MDR1 - & + & - & + & - & + \\
\hline GL3-mt-pro-MDR1 - & - & + & & + & \\
\hline pshRNA-Snail - & - & & + & + & \\
\hline pshRNA-vector - & & & - & - & \\
\hline
\end{tabular}

\begin{tabular}{|c|c|c|c|c|c|c|}
\hline pGL3-wt-pro-miR-122 & - & + & - & + & - & + \\
\hline pGL3-mt-pro-miR-122 & - & - & + & - & + & - \\
\hline pshRNA-Snail & - & - & - & + & + & 一 \\
\hline pshRNA-vector & - & - & - & - & - & + \\
\hline
\end{tabular}

Figure 4. Analyses of the mechanisms underlying the regulation of the transcription of MDR1 and hsa-miRNA-22-3p by Snaill. (A) Analyses of the gene promoter sequences of MDR1 (left) and hsa-miRNA-22-3p (right) as well as bioinformatic analyses of the TFBS sites of Snail1 in the two promoters (B) Validation of the activities of these two promoters. The expression of GFP protein was induced by these two promoters in $293 \mathrm{~T}$ cells after $48 \mathrm{~h}$ of transfection. Left: validation of the MDR1 promoter. Right: validation of the hsa-miRNA-22-3p promoter. (C) Validation of the TFBS binding sites of Snail1 in the MDR1 (left) and miRNA-22-3p (right) promoters using the luciferase reporter gene. ${ }^{* *} \mathrm{P}<0.01$. TFBS, transcription factor binding site.

pri-miRNA22 gene, in the human genome was first acquired. The $2.5 \mathrm{~kb}$ promoter sequence upstream of the transcription initiation sites was obtained. Promoter 2.0 prediction software was used to predict the location of the promoter sequence. The prediction results showed that the promoter was a $443 \mathrm{bp}$ DNA sequence (Fig. 4A). A GFP-expressing plasmid containing the hsa-miRNA-22-3p promoter was then constructed for related tests of promoter activity. The hsa-miRNA-22-3p promoter effectively induced GFP expression in 293T cells (Fig. 4B). The Snaill binding sites in these two promoters were analyzed and predicted using the JASPAR transcription factor binding site prediction software (http://jaspar.genereg.net/). The results showed that Snaill had theoretical transcription factor binding site (TFBS) (Fig. 4A). The TFBS binding sites in the two promoters were validated using a luciferase reporter gene assay. After $48 \mathrm{~h}$ of co-transfection in 293T cells, Snail1 silencing (pshRNA-Snaill transfection) significantly inhibited luciferase activity of the wild-type reporter gene (pGL3wt-pro-MDR1/hsa-miRNA-22-3p) in the transfected cells compared with the wild-type reporter gene alone transfection group, but did not have a significant effect on the luciferase activity in cells transfected with the mutant reporter gene compared with mutant reporter gene alone transfection group (Fig. 4C). These results indicated that Snaill binds to the 
A

\begin{tabular}{llll}
\hline \multirow{2}{*}{ Group } & \multicolumn{3}{c}{$\mathrm{IC}_{50}$ of bortezomib $(48 \mathrm{~h}, \mathrm{nM})$} \\
\cline { 2 - 4 } XG-7/bor & Cell & Lv-NC & Lv-shRNA-Snail \\
\cline { 2 - 4 } RPMI-8226/bor & $68.52 \pm 0.51$ & $63.59 \pm 0.56$ & $12.13 \pm 0.07 * *$ \\
\hline
\end{tabular}

B

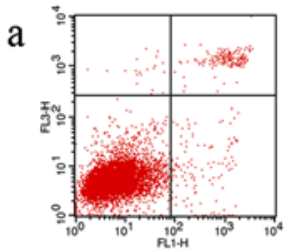

d

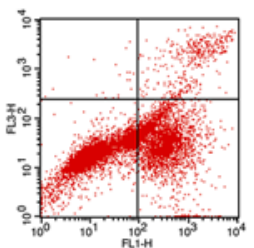

$\mathrm{b}$

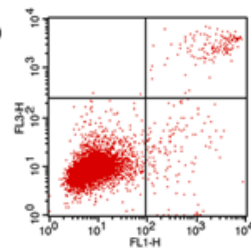

e

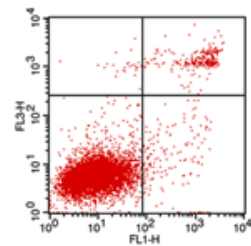

$c$
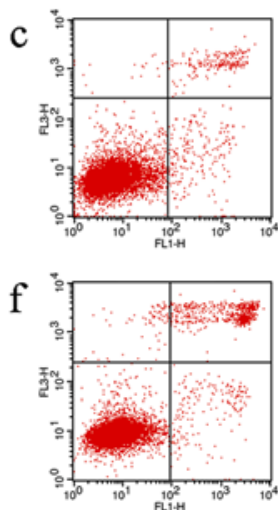

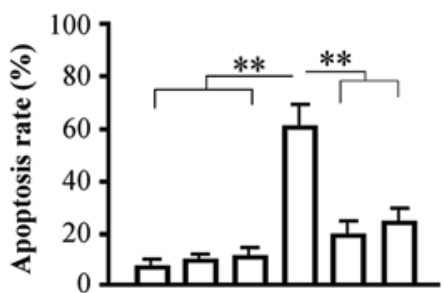

Bortezomib $(10 \mu \mathrm{m})-+++++$

$\mathrm{Lv}-\mathrm{NC}-{ }_{-}+--$

Lv-shRNA-Snail $-\quad-\quad+\quad++$

Lv-MDR1 - $-\quad-+-$

Lv-shRNA-P53 - $-\quad-\quad-+$

$\mathrm{C}$

$$
\text { c }
$$

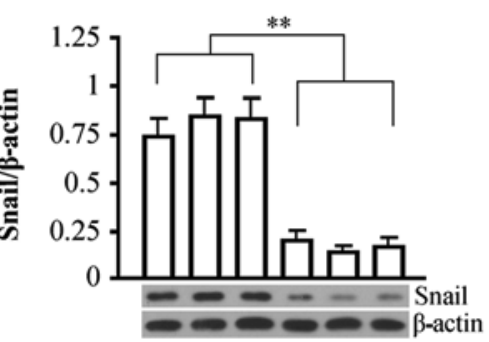

Bortezomib $(10 \mu \mathrm{m})-+++++$

Lv-NC - -+--

Lv-shRNA-Snail $-\quad-+++$

Lv-MDR1 - $-\quad-+$

Lv-shRNA-P53 - $-\quad-\quad+$
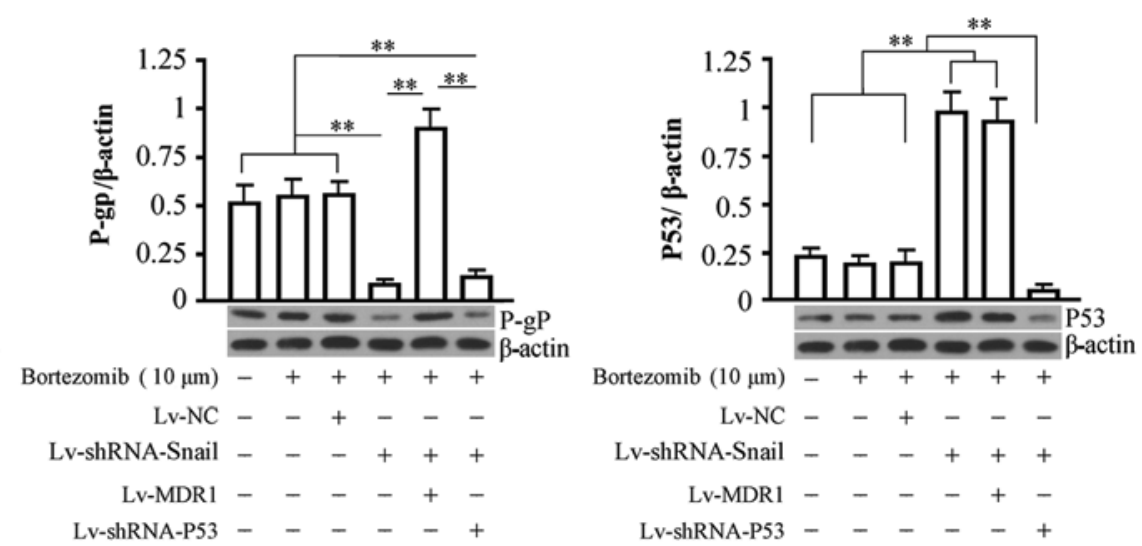

Figure 5. Analyses of $\mathrm{IC}_{50}$, apoptosis and protein expression detection. (A) The effect of Snail1 gene silencing on the $\mathrm{IC}_{50}$ values of bortezomib in XG-7/Bor and RPMI-8226/Bor cells after 48 h. The groups are indicated as follows: Cell, cell control group; Lv-NC, NC control group; Lv-shRNA-Snaill, virus infection group. Cells were infected with recombinant viruses for $72 \mathrm{~h}$. (B) Detection of cell apoptosis in all groups. Left: Raw data of cell detection. The horizontal axis represents fluorescein isothiocyanate (FITC), and the vertical axis represents propidium iodide (PI). The upper right and lower right quandrants indicate late-stage and early-stage apoptosis, respectively. Right: Analyses of apoptosis rates among the groups. The apoptosis rate was the sum of early-stage apoptosis and late-stage apoptosis. a, cell control group without bortezomib; b, cell control group; c, NC control group; d, Snail1-silencing group; e, MDR1-silencing group; f, P53-silencing group. (C) Detection of the expression of Snail1, P-gp, and P53 proteins in all groups of cells. The bottom panels show the target protein bands, and the top panels show the analysis of the relative optical density of the target proteins in all groups of cells. $\beta$-actin was used at the internal control. ${ }^{* * *} \mathrm{P}<0.01$. $\mathrm{IC}_{50}$, half maximal inhibitory concentration.

promoters of MDR1 and hsa-miRNA-22-3p through the TFBS to positively regulate the transcription of these two genes.

Analyses of the pathways of Snaill/MDR1 and Snaill/ hsa-miRNA-22-3p/P53 in bortezomib-resistant MMCs. We performed Snaill gene silencing experiments in two drugresistant cell lines, XG-7/Bor and RPMI-8226/Bor, using the lentiviral approach. The $\mathrm{IC}_{50}$ values of bortezomib in these two drug-resistant cell lines after $48 \mathrm{~h}$ of gene intervention were detected and analyzed. The results showed that the $\mathrm{IC}_{50}$ values of bortezomib in XG-7/Bor and RPMI-8226/Bor cells after $48 \mathrm{~h}$ of Snaill gene silencing decreased significantly from $68.52 \mathrm{nM}$ and $81.24 \mathrm{nM}$ to $12.13 \mathrm{nM}$ and $9.28 \mathrm{nM}$, respectively (Fig. 5A). The cell apoptosis rate in the Snail1silencing group significantly increased after XG-7/Bor cells in all groups were treated with $10 \mathrm{nM}$ bortezomib for $48 \mathrm{~h}$. The cell apoptosis rates in the Snaill-silencing combined with MDR1 expression group and the Snaill-silencing combined with P53-silencing group both significantly decreased (Fig. 5B). After cells were infected with Lv-shRNA-Snaill for $72 \mathrm{~h}$, Snaill and P-gp protein expression was significantly decreased, and P53 protein expression was significantly increased. In the Lv-shRNA-Snaill infection combined with Lv-MDR1 infection group, the Snaill protein expression did not significantly change. In the same group, P-gp protein expression was significantly increased, and P53 protein expression was significantly decreased. In the Lv-shRNASnaill infection combined with Lv-shRNA-P53 infection group, Snaill protein expression did not significantly change. In the same group, P-gp and P53 proteins expression were 
significantly decreased. The combination of the above results showed that Snaill gene silencing significantly enhanced the sensitivity of XG-7/Bor cells to bortezomib and increased cell apoptosis. MDR1 overexpression or P53 silencing significantly reversed the function of Snaill gene silencing in the promotion of bortezomib-induced apoptosis in XG-7/Bor cells. Exogenous MDR1 did not contain the wild-type promoter and was not regulated by Snail1. Similarly, P53 gene silencing was transcriptionally regulated and was not negatively regulated by hsa-miRNA-22-3p. Therefore, Snaill gene silencing inhibited MDR1 and upregulated P53 expression to promote the sensitivity of XG-7/Bor to bortezomib. These results indicate that although the Snail1/MDR1 and Snail1/hsa-miRNA-22-3p/ P53 pathways are regulated by an upstream factor, Snail1, they regulate multi-drug resistance and apoptosis of MMCs via two independent pathways and thus co-dominate the development of bortezomib resistance in MM.

\section{Discussion}

Multiple myeloma (MM) is one of the most common malignant tumors in the hematological system, and its incidence accounts for $10 \%$ of the total number of malignant tumors in the hematological system $(1,11)$. Currently, there is no effective clinical measure that can completely cure MM. The commonly used treatment methods for MM include chemotherapy, radiotherapy, hematopoietic stem cell transplantation, and combined treatment using these methods. Various targeted formulations are used for the chemotherapy of MM. The approval of the clinical use of the proteasome inhibitor, bortezomib, was important for the chemotherapy strategy for MM. Bortezomib not only directly inhibits the proliferation of multiple myeloma cells (MMCs) and induces apoptosis but also improves the chemotherapy sensitivity of drug-resistant MMCs to dexamethasone, melphalan and thalidomide (14). Bortezomib is the first proteasome inhibitor approved by the FDA to treat recurrent and refractory $\mathrm{MM}$. The single-drug effective rate of bortezomib in the treatment of MM is approximately $30 \%$. When bortezomib is used in combination with dexamethasone or immunomodulators, the effective rate increases to more than $60 \%$. The 2008 National Comprehensive Cancer Network (NCCN) guideline listed bortezomib single-drug and its combination with liposomal doxorubicin as the category I preferred regimen and bortezomib + dexamethasone as the category $2 \mathrm{~A}$ preferred regimen (15). As the first-line drug for MM treatment, bortezomib has its own advantages (16). Although the chemotherapy regimen based on bortezomib significantly improves the related symptoms of MM patients within a short time period and delays tumor progression, almost all MM patients with bortezomib administration exhibit drug resistance features after bortezomib medication for a period of time, which greatly limits the long-term efficacy of bortezomib in MM (17). Currently, basic studies on drug resistance in MM chemotherapy indicate that the mechanisms underlying the development of drug resistance in MM chemotherapy might be associated with $\mathrm{NF}-\kappa \mathrm{B}$ activity as well as overexpression of heat shock proteins and BCL protein family members (18-20). However, these previous studies did not provide complete, in-depth, and systematic elucidation of the development of MM clinical drug resistance mechanisms.
Thus, additional studies on the mechanisms of drug resistance in MM chemotherapy are required. Using the drug resistance theory studies as guidance, improvement of drug resistance mechanisms, screening and demonstration of key gene targets to improve drug resistance as well as searching for effective regimens to prevent the development of drug resistance or eradicate malignant plasma cells are important directions for studies on the treatment theory of MM in the future. At present, there are few studies on the drug resistance mechanism of MM to bortezomib. Thus, the drug resistance mechanism remains unclear, and there is no effective clinical solution.

The Snail superfamily has been highly conserved during the evolution of vertebrates. The human Snail1 protein is composed of 264 amino acids. The Snaill protein has an amino-terminal basic amino acid-rich domain and a carboxyl-terminal DNA-binding domain, and these two special domains regulate its interaction with co-repressors and the epigenetic remodeling complex and DNA binding, respectively. A serine rich domain (SRD) and nuclear export sequence (NSE) control the stability and subcellular location of the Snaill protein (21). As a transcription factor, snaill functions through binding to the E-box element of the 5'-CANNTG-3' core base sequence in the promoter region of many tumor-related genes (22). Snail1 can promote or inhibit the transcription of E-cadherin, IL-8 and CD147 to regulate the epithelial-mesenchymal transition (EMT) process of many tumors (23-25). The Snail family contains three family members, namely Snail1, Snail2 and Snail3. Studies in recent years have indicated that Snaill plays a critical role in the development and regulation of drug resistance mechanisms in tumors. The expression of Snaill protein in non-small cell lung cancer (NSCLC) positively correlates with the expression of drug resistance-related genes. Blocking Snail1 in the A549 lung cancer cell line effectively reverses the multiple drug resistance characteristics of lung cancer. Snaill expression was found to be significantly increased in the H446/CDDP NSCLC cell line compared to that in the H446 cell line, indicating that the drug resistance of NSCLC to cisplatin might be associated with the high expression of Snaill. Therefore, Snaill can be used as a new target for clinical treatment of drug-resistant lung cancer patients $(26,27)$. The high Snail1 expression in bladder cancer tissues has a significant positive correlation with ERCC1 (28). Furthermore, Snail1 has also been confirmed to be a promotion factor (29) for the development of drug resistance mechanisms in breast cancer (30) and prostate cancer (31). P53 is currently one of the most extensively studied genes. Wild-type P53 is a tumor-suppressor gene, and it is a negative regulatory factor in cell growth cycles and inhibits tumor development (32). Studies on P53 gene functions in recent years have indicated that P53 and many factors have mutual regulation functions and can regulate and improve the sensitivity of tumor cells to the treatment of various chemotherapeutic drugs (33). One recent study has indicated that loss of P53 causes the abnormal expression of the RNA-binding protein HnRNPA0 to eventually result in the development of drug resistance in various tumor cells to chemotherapy that can kill them (34). In addition, P53 has also been confirmed to directly or indirectly participate in the development of drug resistance mechanisms in many types of tumors (35). 
The multidrug resistance (MDR) phenomenon refers to the development of multiple drug resistance in tumor cells after development of drug resistance to one chemotherapeutic drug. In other words, tumor cells will develop different levels of drug resistance to other antitumor drugs that have different structures or different targets. The MDR of tumor cells is an important reason causing the ineffectiveness of antitumor drug treatment. The abnormal expression of MDR and its expression product, P-glycoprotein, is considered one of the major reasons for the development of MDR in tumor cells. The human MDR gene family includes MDR1 and MDR2. MDR1 is associated with drug resistance in various types of malignant tumors, but MDR2 cannot cause tumor cells to develop drug resistance (36). P-gp is an important expression product of the MDR gene. P-gp is an adenosine triphosphate (ATP)dependent efflux pump, and it has an ATP-binding site. When tumor cells come into contact with antitumor drugs, lipidsoluble drugs enter into cells with the concentration gradient. P-gp binds to drug molecules and connects the molecules to the ATP-binding site to form a phosphorylated and glycosylated ATP-binding cassette of drug macromolecules. During ATP hydrolysis, the released energy pumps drugs that enter into cells outside cells to decrease the drug concentration in tumor cells. Therefore, MDR1 expression in the body of tumor patients is associated with MDR of tumor cells. Exogenous substances, such as natural hydrophobic antitumor drugs including anthracyclines, vincristine alkaloids, epipodophyllotoxin, actinomycin D and paclitaxel, are easily pumped out by MDR1 to reduce the drug concentration in cells, decrease the antitumor cytotoxicity, and promote drug resistance. It has also been shown that the drug resistance levels of tumor cells, intracellular drug concentrations, and MDR expression on the surface of the cell membrane are closely associated (37). Blockade of MDR1 using calcium channel blockers significantly inhibits the efflux of drugs to increase the aggregation of drugs in cells, reverse drug resistance of cells, and increase the sensitivity of tumor cells to chemotherapeutic drugs (38). The function of miRNAs in drug resistance mechanisms in tumors is always an important direction in tumor drug resistance studies (39-41).

Hsa-miRNA22 localizes to human chromosome 17.Current studies on hsa-miRNA22 in tumors have mainly focused on its regulation in tumor progression $(42,43)$. However, there is no report on the association of hsa-miRNA-22 with blood tumors and their drug resistance mechanisms.

This study is the first systematic study to focus on the critical role of the Snaill nuclear transcription factor in the development of drug resistance mechanisms to bortezomib in MM and the first to elucidate the Snail1/MDR1 and Snail1/ hsa-miRNA-22-3p/P53 drug resistance mechanism regulatory pathways. The results have extraordinary significance in the development of highly efficient therapeutic methods in the clinical treatment of MM using bortezomib. Taking into consideration the significant association between Snaill and bortezomib-resistance in MM, we think that understanding the action mechanism of Snaill in bortezomib-resistance is critical to the development of the clinical therapy of MM by using gene therapy combined with bortezomib. Therefore, to ascertain whether the increase in Snaill expression is directly associated with the development of bortezomib drug resistance mechanisms in MM, we silenced the Snaill gene using a lentiviral experimental system in two bortezomib-resistant MM cell lines, XG-7/Bor and RPMI-8226/Bor. The $\mathrm{IC}_{50}$ values (48 h) of bortezomib in the drug-resistant XG-7/Bor and RPMI8226/Bor cell lines decreased from $68.5 \mathrm{nM}$ and $81.2 \mathrm{nM}$ to $12.1 \mathrm{nM}$ and $9.4 \mathrm{nM}$, respectively, indicating that Snail1 silencing significantly reversed the drug resistance of MMCs to bortezomib. We next performed deep mining on transcriptome data. Combined with association analysis of drug resistancerelated genes, the pathways of Snaill that influenced drug resistance were investigated. Data analyses showed that Snail1 was associated with the expression of the MDR1 gene and P53 protein, respectively. MDR1 and P53 are functional genes that are directly associated with drug resistance (44). Therefore, this study investigated whether the expression of MDR1 and P53 are directly associated with Snaill and whether they are in the pathways of drug resistance improvement by Snail silencing. The transcription and protein expression levels of MDR1 and P53 suggest that the association between Snail1 and MDR1 was at the transcription level (its mRNA and protein levels were consistently changed) at that P53 was posttranscriptionally regulated (its mRNA level was not changed but the protein content was changed). Since Snaill is a transcription factor, we have a reason to think that Snaill may regulate MDR1 transcription by binding to its promoter, and may bind to various promoters of miRNAs and thus negatively regulate $\mathrm{P} 53$ expression by stimulating the transcription of this miRNA, that is, the former is direct regulation, and the latter is indirect regulation. A series of bioinformatic prediction data indicated that the MDR1 gene promoter contains a TFBS of Snail1 and that the regulation of P53 expression by Snaill might be mediated by hsa-miRNA-22-3p. The findings also suggest that there is a TFBS of Snaill in the promoter region of the hsa-miRNA-22-3p precursor sequence and that the 3'UTR region of the P53 gene has a hsa-miRNA-22-3p-binding site (seed region). Therefore, we hypothesize that inactivation of the regulation of the Snail1/MDR1 and Snail1/hsa-miRNA22-3p/P53 pathways occurs during development of bortezomib drug resistance mechanisms in MM and that silencing of Snaill effectively reverses the drug resistance of bortezomibresistant MMCs through the inhibition of MDR1 transcription and promotion of P53 protein expression. Elucidation of the above-mentioned drug resistance mechanisms and regulatory pathways will provide a solid theoretical basis for the treatment of MM by Snaill-based gene intervention combined with bortezomib.

The development of drug resistance mechanisms results from the combination of the comprehensive functions of multiple factors. After confirmation of the leading functional routes and regulatory pathways, we can start at the upstream pathways to look for more high-efficient gene targets to improve the clinical efficacy of bortezomib using gene intervention methods. The most significant conclusion of this study is that Snaill gene silencing can effectively increase the sensitivity of two groups of bortezomib-resistant MMCs to bortezomib, which provides a theoretical basis for highefficient therapy using genes combined with bortezomib to target MM using Snaill as the gene target. The most evident feature of this high-efficient therapy is to improve the rapid development of bortezomib drug resistance mechanisms in 
MMCs to the maximum extent. The reasons for the enhancement of Snail1 expression in bortezomib-resistant MMCs were not further analyzed, but future studies in this direction are planned. However, that does not affect the significance of this study at this stage. In addition, this study on hsa-miRNA22-3p first demonstrated its association with drug resistance in tumors. These results suggest that hsa-miRNA-22-3p has the potential to become a biomarker for screening the bortezomib drug-resistant population in MM patients, which has important significance in the development of drug administration methods and comprehensive therapy methods for treatment of MM patients. Therefore, related studies on hsa-miRNA-22-3p in bortezomib drug resistance is also an important direction for our future studies.

Overall, this study elucidated the function of Snail1 in the development of bortezomib drug resistance mechanisms in MM, confirmed the drug resistance regulatory pathways of Snail1/ MDR1 and Snail1/hsa-miRNA-22-3p/P53, and preliminarily established a method to improve the sensitivity of bortezomibresistant MMCs to bortezomib treatment by silencing the Snail1 gene. These findings shed light on the development of drug resistance mechanisms to bortezomib in MM and provide information that may increase the clinical efficacy of bortezomib and improve the poor prognosis of MM patients.

\section{Acknowledgements}

This research was supported by the Central Laboratory of the First Affiliated Hospital of Anhui Medical University.

\section{Funding}

The present study was supported by the Anhui Provincial Natural Science Foundation of China (grant no. 1208085QH154 and 1708085MH224).

\section{Availability of data and materials}

The datasets used and/or analyzed during the current study are available from the corresponding author on reasonable request.

\section{Authors' contributions}

$\mathrm{ZH}$ was responsible for the formulation of the research plan, the analysis of the results and the writing of the manuscript. $\mathrm{ZH}, \mathrm{XL}, \mathrm{WW}$ and $\mathrm{XC}$ were specifically responsible for the implementation of the plan, including cell culture, collection of patient data, testing of drug resistance genes and other tests and the statistical analysis of the results. QZ, MY, JG and RX were responsible for the revision of the plan, guidance of the tests, the evaluation of the results and the revision of the manuscript. All authors read and approved the manuscript and agree to be accountable for all aspects of the research in ensuring that the accuracy or integrity of any part of the work are appropriately investigated and resolved.

\section{Ethics approval and consent to participate}

The study was approved by the Medical Ethics Committee of the First Affiliated Hospital of Anhui Medical University.

\section{Patient consent for publication}

Not applicable.

\section{Competing interests}

The authors declare that they have no competing interests.

\section{References}

1. Meister S, Schubert U, Neubert K, Herrmann K, Burger R, Gramatzki M, Hahn S, Schreiber S, Wilhelm S, Herrmann M, et al: Extensive immunoglobulin production sensitizes myeloma cells for proteasome inhibition. Cancer Res 67: 1783-1792, 2007.

2. Griffin PT, Ho VQ, Fulp W, Nishihori T, Shain KH, Alsina M and Baz RC: A comparison of salvage infusional chemotherapy regimens for recurrent/refractory multiple myeloma. Cancer 121: 3622-3630, 2015

3. Nikesitch $\mathrm{N}$ and Ling SC: Molecular mechanisms in multiple myeloma drug resistance. J Clin Pathol 69: 97-101, 2016.

4. Adams J: The proteasome: A suitable antineoplastic target. Nat Rev Cancer 4: 349-360, 2004.

5. Chauhan D and Anderson KC: Mechanisms of cell death and survival in multiple myeloma (MM): Therapeutic implications. Apoptosis 8: 337-343, 2003.

6. Qin JZ,Ziffra J, Stennett L, Bodner B, Bonish BK, Chaturvedi V, Bennett F, Pollock PM, Trent JM, Hendrix MJ, et al: Proteasome inhibitors trigger NOXA-mediated apoptosis in melanoma and myeloma cells. Cancer Res 65: 6282-6293, 2005.

7. Roccaro AM, Hideshima T, Raje N, Kumar S, Ishitsuka K, Yasui H, Shiraishi N, Ribatti D, Nico B, Vacca A, et al: Bortezomib mediates antiangiogenesis in multiple myeloma via direct and indirect effects on endothelial cells. Cancer Res 66: 184-191, 2006.

8. Murray MY, Auger MJ and Bowles KM: Overcoming bortezomib resistance in multiple myeloma. Biochem Soc Trans 42: 804-808, 2014

9. Zhou W, Yang Y, Xia J, Wang H, Salama ME, Xiong W, Xu H, Shetty S, Chen T, Zeng Z, et al: NEK2 induces drug resistance mainly through activation of efflux drug pumps and is associated with poor prognosis in myeloma and other cancers. Cancer Cell 23: 48-62, 2013.

10. Yu W, Chen Y, Xiang R, Xu W, Wang Y, Tong J, Zhang N, Wu Y and Yan H: Novel phosphatidylinositol 3-kinase inhibitor BKM120 enhances the sensitivity of multiple myeloma to bortezomib and overcomes resistance. Leuk Lymphoma 58: 428-437, 2017.

11. Abe M: Multiple myeloma. Nihon Rinsho 67: 991-995, 2009 (In Japanese).

12. Tomono T, Yano K and Ogihara T: Snail-induced epithelialto-mesenchymal transition enhances P-gp-mediated multidrug resistance in HCC827 cells. J Pharm Sci 106: 2642-2649, 2017.

13. Cho JH, Lee SJ, Oh AY, Yoon MH, Woo TG and Park BJ: NF2 blocks Snail-mediated p53 suppression in mesothelioma. Oncotarget 6: 10073-10085, 2015.

14. Abdi J, Chen G and Chang H: Drug resistance in multiple myeloma: Latest findings and new concepts on molecular mechanisms. Oncotarget 4: 2186-2207, 2013.

15. Gaultney JG, Ng TW, Uyl-de Groot CA, Sonneveld P, van Beers EH, van Vliet MH and Redekop WK: Potential therapeutic and economic value of risk-stratified treatment as initial treatment of multiple myeloma in Europe. Pharmacogenomics 19: 213-226, 2018.

16. Wu T, Zhou J, Wang C, Wang B, Zhang S and Bai H: Bortezomib overcomes the negative prognostic impact of renal impairment in a newly diagnosed elderly patient with multiple myeloma: A case report. Oncol Lett 14: 7318-7322, 2017.

17. Gavriatopoulou M, Terpos E, Kastritis E and Dimopoulos MA: Efficacy and safety of elotuzumab for the treatment of multiple myeloma. Expert Opin Drug Saf 16: 237-245, 2017.

18. Adam Z, Sčudla V, Krejčí M, Cermáková Z, Pour L and Král Z: Treatment of AL amyloidosis in 2012; the benefit of new drugs (bortezomib, thalidomide, and lenalidomide). Summary of published clinical trials. Vnitr Lek 59: 37-58, 2013 (In Czech). 
19. Abidi MH, Gul Z, Abrams J, Ayash L, Deol A, Ventimiglia M, Lum L, Mellon-Reppen S, Al-Kadhimi Z, Ratanatharathorn V, et al: Phase I trial of bortezomib during maintenance phase after high dose melphalan and autologous stem cell transplantation in patients with multiple myeloma. J Chemother 24: 167-172, 2012.

20. Jacob P, Hirt $\mathrm{H}$ and Bendahmane A: The heat-shock protein/ chaperone network and multiple stress resistance. Plant Biotechnol J 15: 405-414, 2017.

21. Carmichael CL and Haigh JJ: The Snail family in normal and malignant haematopoiesis. Cells Tissues Organs 203: 82-98, 2017.

22. Nieto MA: The snail superfamily of zinc-finger transcription factors. Nat Rev Mol Cell Biol 3: 155-166, 2002.

23. Cheng CW, Wu PE, Yu JC, Huang CS, Yue CT, Wu CW and Shen CY: Mechanisms of inactivation of E-cadherin in breast carcinoma: Modification of the two-hit hypothesis of tumor suppressor gene. Oncogene 20: 3814-3823, 2001.

24. Argast GM, Krueger JS, Thomson S, Sujka-Kwok I, Carey K, Silva S, O'Connor M, Mercado P, Mulford IJ, Young GD, et al Inducible expression of TGF $\beta$, snail and Zeb1 recapitulates EMT in vitro and in vivo in a NSCLC model. Clin Exp Metastasis 28 593-614, 2011.

25. Barnett $P$, Arnold RS, Mezencev R, Chung LW, Zayzafoon M and Odero-Marah V: Snail-mediated regulation of reactive oxygen species in ARCaP human prostate cancer cells. Biochem Biophys Res Commun 404: 34-39, 2011.

26. Wang H, Zhang G, Zhang H, Zhang F, Zhou B, Ning F, Wang HS Cai SH and Du J: Acquisition of epithelial-mesenchymal transition phenotype and cancer stem cell-like properties in cisplatin-resistant lung cancer cells through AKT/ $\beta$-catenin/ Snail signaling pathway. Eur J Pharmacol 723: 156-166, 2014.

27. Zhang K, Wang X and Wang H: Effect and mechanism of Src tyrosine kinase inhibitor sunitinib on the drug-resistance reversal of human A549/DDP cisplatin-resistant lung cancer cell line. Mol Med Rep 10: 2065-2072, 2014.

28. Kawashima A, Takayama H, Kawamura N, Doi N, Sato M, Hatano K, Nagahara A, Uemura M, Nakai Y, Nishimura K. et al: Co-expression of ERCC1 and Snail is a prognostic but not predictive factor of cisplatin-based neoadjuvant chemotherapy for bladder cancer. Oncol Lett 4: 15-21, 2012.

29. Brozovic A: The relationship between platinum drug resistance and epithelial-mesenchymal transition. Arch Toxicol 91: 605-619, 2017.

30. Semina SE, Scherbakov AM, Kovalev SV, Shevchenko VE and Krasil'nikov MA: Horizontal transfer of tamoxifen resistance in MCF-7 cell derivates: Proteome study. Cancer Invest 35: 506-518, 2017

31. Ware KE, Somarelli JA, Schaeffer D, Li J, Zhang T, Park S, Patierno SR, Freedman J, Foo WC, Garcia-Blanco MA, et al: Snail promotes resistance to enzalutamide through regulation of androgen receptor activity in prostate cancer. Oncotarget 7 : 50507-50521, 2016.
32. Zhan M, Yu D, Lang A, Li L and Pollock RE: Wild type p53 sensitizes soft tissue sarcoma cells to doxorubicin by downregulating multidrug resistance-1 expression. Cancer 92: $1556-1566,2001$

33. Hasna J, Hague F, Rodat-Despoix L, Geerts D, Leroy C, Tulasne D, Ouadid-Ahidouch $\mathrm{H}$ and Kischel P: Orai3 calcium channel and resistance to chemotherapy in breast cancer cells: The p53 connection. Cell Death Differ 25: 691-705, 2018.

34. Cannell IG, Merrick KA, Morandell S, Zhu CQ, Braun CJ, Grant RA, Cameron ER, Tsao MS, Hemann MT and Yaffe MB: A pleiotropic RNA-binding protein controls distinct cell cycle checkpoints to drive resistance of p53-defective tumors to chemotherapy. Cancer Cell 28: 831, 2015.

35. Luanpitpong S, Angsutararux P, Samart P, Chanthra N, Chanvorachote P and Issaragrisil S: Hyper-O-GlcNAcylation induces cisplatin resistance via regulation of p53 and c-Myc in human lung carcinoma. Sci Rep 7: 10607, 2017.

36. Singh MS, Tammam SN, Shetab Boushehri MA and Lamprecht A: MDR in cancer: Addressing the underlying cellular alterations with the use of nanocarriers. Pharmacol Res 126: 2-30, 2017.

37. Montazami N, Aghapour M, Farajnia S and Baradaran B: New insights into the mechanisms of multidrug resistance in cancers. Cell Mol Biol (Noisy-le-grand) 61: 70-80, 2015.

38. Mancuso MR and Massarweh SA: Endocrine therapy and strategies to overcome therapeutic resistance in breast cancer. Curr Probl Cancer 40: 95-105, 2016.

39. Bach DH, Hong JY, Park HJ and Lee SK: The role of exosomes and miRNAs in drug-resistance of cancer cells. Int J Cancer 141: 220-230, 2017

40. Çalışkan M, Güler H and Bozok Çetintaş V: Current updates on microRNAs as regulators of chemoresistance. Biomed Pharmacother 95: 1000-1012, 2017.

41. Leivonen SK, Icay K, Jäntti K, Siren I, Liu C, Alkodsi A Cervera A, Ludvigsen M, Hamilton-Dutoit SJ, d'Amore F, et al: MicroRNAs regulate key cell survival pathways and mediate chemosensitivity during progression of diffuse large B-cell lymphoma. Blood Cancer J 7: 654, 2017.

42. Fan W, Huang J, Xiao H and Liang Z: MicroRNA-22 is downregulated in clear cell renal cell carcinoma, and inhibits cell growth, migration and invasion by targeting PTEN. Mol Med Rep 13: 4800-4806, 2016.

43. Wang J, Li Y, Ding M, Zhang H, Xu X and Tang J: Molecular mechanisms and clinical applications of miR-22 in regulating malignant progression in human cancer (Review). Int J Oncol 50: 345-355, 2017.

44. JThottassery JV, Zambetti GP, Arimori K, Schuetz EG and Schuetz JD: p53-dependent regulation of MDR1 gene expression causes selective resistance to chemotherapeutic agents. Proc Nat Acad Sci USA 94: 11037-11042, 1997. 